\title{
Mediterranean Diet and Bladder Cancer Risk in Italy
}

\author{
Francesca Bravi ${ }^{1}$ (D), Maria-Eleni Spei ${ }^{2}$, Jerry Polesel ${ }^{3}$ (D), Matteo Di Maso ${ }^{1,4}$, \\ Maurizio Montella ${ }^{5}$, Monica Ferraroni ${ }^{1}$ (D), Diego Serraino ${ }^{3}$, Massimo Libra ${ }^{6}$, Eva Negri ${ }^{7}$, \\ Carlo La Vecchia ${ }^{1, *}$ (iD) and Federica Turati ${ }^{1}$ (iD
}

1 Department of Clinical Sciences and Community Health, Università degli Studi di Milano, 20133 Milan, Italy; francesca.bravi@unimi.it (F.B.); matteo.dimaso@unimi.it (M.D.M.); monica.ferraroni@unimi.it (M.F.); federica.turati@unimi.it (F.T.)

2 Department of Hygiene, Epidemiology and Medical Statistics, School of Medicine, National and Kapodistrian University of Athens, 11527 Athens, Greece; marilena_0108@hotmail.com

3 Unit of Cancer Epidemiology, IRCCS CRO Aviano National Cancer Institute, 33081 Aviano, Italy; polesel@cro.it (J.P.); serrainod@cro.it (D.S.)

4 Department of Public Health and Pediatric Sciences, Università degli Studi di Torino, CTO Hospital, 10126 Turin, Italy

5 Unit of Epidemiology, Istituto Tumori Fondazione Pascale IRCCS, 80131 Naples, Italy; m.montella@istitutotumori.na.it

6 Laboratory of Translational Oncology \& Functional Genomics, Department of Biomedical and Biotechnological Sciences, Università di Catania, 95124 Catania, Italy; m.libra@unict.it

7 Department of Biomedical and Clinical Sciences, Università degli Studi di Milano, 20157 Milan, Italy; eva.negri@unimi.it

* Correspondence: carlo.lavecchia@unimi.it; Tel.: +39-02-5032-0863; Fax: +39-02-5032-0866

Received: 11 July 2018; Accepted: 8 August 2018; Published: 10 August 2018

\begin{abstract}
Previous studies have reported that Mediterranean diet is inversely related to the risk of several neoplasms; however, limited epidemiological data are available for bladder cancer. Thus, we examined the association between Mediterranean diet and this neoplasm in an Italian multicentric case-control study consisting of 690 bladder cancer cases and 665 controls. We assessed the adherence to the Mediterranean diet via a Mediterranean Diet Score (MDS), which represents the major characteristics of the Mediterranean diet and ranges from 0 to 9 (from minimal to maximal adherence, respectively). We derived odds ratios (ORs) of bladder cancer according to the MDS score from multiple logistic regression models, allowing for major confounding factors. The ORs of bladder cancer were 0.72 (95\% confidence interval, CI, 0.54-0.98) for MDS of 4-5 and 0.66 ( $95 \%$ CI, $0.47-0.93$ ) for MDS of 6-9 ( $p$ for trend $=0.02$ ) compared to MDS $=0-3$. Results were similar in strata of sex, age, and education, while the risk appeared somewhat lower in never-smokers and patients with pT1-pT4 bladder carcinomas. Among individual components of the MDS, we observed inverse associations for greater consumption of legumes, vegetables, and fish. In our study, which was carried out on an Italian population, the higher adherence to the Mediterranean diet was related to a lower risk of bladder cancer.
\end{abstract}

Keywords: Mediterranean diet; bladder cancer; case-control; prevention

\section{Introduction}

Bladder cancer is the ninth most common neoplasm in the world, particularly in high-income countries and among men [1]. The best recognized risk factor is tobacco smoking, accounting for $30-45 \%$ of cases among men and $25-30 \%$ of cases among women in Europe and North America [2]. Other relevant risk factors for bladder cancer are occupational exposure to aromatic amines, 
Schistosoma haematobium and other chronic bladder infections, phenacetin-containing analgesics, history of metabolic syndrome, history of diabetes, and genetic predisposition [3-10].

Diet may influence bladder carcinogenesis, since many metabolites of foods are excreted through the urinary tract, such as chlorination byproducts and arsenic in drinking tap water [7]. In addition, some studies have reported inverse relationships-generally of weak to moderate magnitude-with consumption of vegetables and fruit $[3,11,12]$ as well as some micronutrients and bioactive compounds present in plant foods, such as vitamin A, vitamin C, vitamin E, folate [3], carotenoids [13], and flavonoids [14]; however, the evidence of this is inconclusive [15]. Coffee drinking and use of artificial sweeteners have been largely investigated, but any relevant association can now be excluded $[7,16]$.

The so-called Mediterranean diet—defined as the dietary pattern of populations bordering the Mediterranean area-is a plant-centered diet that is rich in olive oil, fruits, vegetables, legumes, and whole grain cereals $[17,18]$. It has been recently recognized as a sustainable lifestyle model [19] and favorably related to all-cause mortality and multiple health outcomes, including cardiovascular diseases, diabetes, and cancer, in particular of the digestive tract [20-23]. To date, only two studies have investigated the role of this dietary pattern on bladder cancer, and their findings were suggestive of an inverse weak relationship that was apparently stronger among smokers $[24,25]$ and possibly restricted to invasive tumors [25]. However, these studies were mainly carried out outside the Mediterranean area where proper adherence to this dietary pattern is limited. We therefore further explored this issue in a Mediterranean population.

\section{Materials and Methods}

\subsection{Participants and Data Collection}

The present analyses are based on a hospital-based case-control study carried out in four Italian areas-Milan, Pordenone, Naples, and Catania-in 2003-2014 [26]. Cases consisted of 690 patients (595 men and 95 women) with incident diagnosis of urothelial carcinoma of the bladder and without previous history of other neoplasms (age range: 25-84 years, median: 67 years,), recruited in major general hospitals. Most cancer cases were histologically verified $(n=642,93 \%)$. According to the 2016 World Health Organization (WHO) grading system [27], 38.8\% of cases $(n=268)$ were noninvasive (i.e., TNM pTis/pTa); $27.8 \%$ were pT1 $(n=192)$ and 23.0\% $(n=159)$ were muscle-invasive (i.e., pT2-pT4); $44.5 \%$ of cases $(n=307)$ were moderately or well differentiated (grading, G1-G2) and $45.2 \%(n=312)$ were undifferentiated or poorly differentiated (G3-G4).

Controls consisted of 665 subjects (561 men and 104 women), identified among patients admitted to the same hospitals for various non-neoplastic acute diseases that were not associated to tobacco smoking or alcohol drinking and not related to long-term dietary changes (median age: 66 years, range: $27-84$ years). Among controls, $22.1 \%$ were admitted for nontraumatic orthopedic disorders, $28.9 \%$ for traumas, $39.3 \%$ for acute surgery, and $9.8 \%$ for various other illnesses.

We submitted the study protocol to the Board of Ethics of the participating hospitals, which gave their approval, and all participants provided a written informed consent.

Participants' information were collected during the hospital stay by trained interviewers using a structured questionnaire. More than $95 \%$ of eligible cases and controls agreed to participate. In particular, data concerning sociodemographic characteristics, anthropometric parameters, lifetime tobacco and alcohol consumption, occupational exposure to specific chemical substances, and personal medical history of selected diseases were registered. Specifically, dietary habits in the two years preceding diagnosis for cases or interview for controls was evaluated using a valid and reproducible food frequency questionnaire (FFQ), including 80 foods and recipes as well as different types of alcoholic beverages $[28,29]$. Subjects were requested to report their habitual frequency of consumption per week for each item. Occasional consumption, i.e., frequency greater than one per month and lower 
than one per week, was considered as 0.5 per week. We used an Italian food composition database to obtain estimates of nutrient and total energy intakes [30,31].

\subsection{Mediterranean Diet Score}

We evaluated the adherence to the Mediterranean diet through the score proposed by Trichopoulou et al. [32] based on nine dietary components. Operatively, the method consists of assigning a value of 0 or 1 to each score components depending on consumption of study participants. In particular, for components typical of the Mediterranean diet (namely, fruits and nuts, vegetables, legumes, cereals, fish and seafood, and high monounsaturated/saturated fatty acids ratio), a value of 1 is given to subjects with an intake greater or equal to the sex-specific median, while a value of 0 is given to participants with an intake lower than the median. Conversely, for components that are not typical of the Mediterranean diet (namely, dairy products and meats), a value of 1 is given to subjects with a consumption lower than sex-specific median, whereas a value of 0 is given to subjects with a consumption greater than the median. As for alcohol consumption, men are given a value of 1 if they consumed between 10 and $50 \mathrm{~g}$ of ethanol/day and 0 otherwise, while women are given a value of 1 if they consumed between 5 and $25 \mathrm{~g}$ of ethanol/day and 0 otherwise. We then obtained the Mediterranean Diet Score (MDS) summing the nine components' values. Therefore, the score ranges between 0 and 9 (representing minimal and maximal adherence, respectively).

\subsection{Statistical Analysis}

We assessed the differences between cases and controls in terms of categories of the main covariates using the $\chi^{2}$ test. We derived the odd ratios (ORs) —and their 95\% confidence intervals (CIs)—of bladder cancer according to the MDS (in categories $0-3,4-5,6-9$, and for 1 point increment) and according to its individual components fitting unconditional logistic regression models, adjusting for sex, age (5-years categories), year of interview (as a continuous variable), study center, years of schooling $(<7,7-11$, $\geq 12$ ), body mass index (BMI, categories of $<20 \mathrm{~kg} / \mathrm{m}^{2}, 20-24.9 \mathrm{~kg} / \mathrm{m}^{2}, 25-29.9 \mathrm{~kg} / \mathrm{m}^{2}$ and $\geq 30 \mathrm{~kg} / \mathrm{m}^{2}$ ), tobacco smoking (categories of never-smokers, ex-smokers, current smokers of $<15$ cigarettes/day, 15-24 cigarettes/day, or 25 cigarettes/day), nonalcoholic energy intake (based on quartiles among controls), history of cystitis, history of diabetes, and family history of bladder cancer. We selected the adjustment variables included in the models on the basis of a priori knowledge. We also estimated the ORs for 1-point increment of the score in strata of sex, age, years of schooling, tobacco smoking, and tumor characteristics. We assessed the heterogeneity across strata using likelihood ratio tests.

We estimated the proportion of bladder cancer cases that would have been avoided if all subjects were in the highest category of adherence to the Mediterranean diet (i.e., MDS: 6-9) using the population attributable fraction (PAF) according to the method proposed by Bruzzi et al. [33]. We computed the 95\% CI for the PAF using the method described by Benichou and Gail [34,35]. Moreover, we estimated the PAF of shifting subjects to the lower adjacent MDS category (i.e., from 0-3 to 4-5, or 4-5 to 6-9) [36]. We carried out all the analyses with SAS 9.4 statistical software (SAS Institute, Cary, NY, USA).

\section{Results}

Among cancer cases, $86.2 \%$ were men and $63.1 \%$ were older than 65 years. Cases and controls were similar in terms of education $(p=0.80)$, while cases were more frequently current smokers (heavy smokers were $10.1 \%$ among cases and $3.5 \%$ among controls; $p<0.01$ ) and reported more often a history of cystitis $(p=0.04)$ and diabetes $(p<0.01)$ compared to controls. Moreover, family history of bladder cancer $(p=0.05)$ and alcohol drinking $(p=0.05)$ tended to be more frequent in cases than controls (Table 1). 
Table 1. Distribution of 690 cases of bladder cancer and 665 controls according to age, sex, education, and other selected variables. Italy, 2003-2014.

\begin{tabular}{|c|c|c|c|}
\hline Characteristics & Cases $n(\%)$ & Controls $n(\%)$ & $\chi^{2}$ Test $^{a}$ \\
\hline \multicolumn{4}{|l|}{ Centre } \\
\hline Milan & $241(34.9)$ & $238(35.8)$ & \\
\hline Pordenone & $242(35.1)$ & $250(37.6)$ & \\
\hline Naples & $129(18.7)$ & $100(15.0)$ & \\
\hline Catania & $78(11.3)$ & $77(11.6)$ & \\
\hline \multicolumn{4}{|l|}{ Sex } \\
\hline Men & $595(86.2)$ & $561(84.4)$ & \\
\hline Women & $95(13.8)$ & $104(15.6)$ & \\
\hline \multicolumn{4}{|l|}{ Age (years) } \\
\hline$<60$ & $148(21.5)$ & $178(26.8)$ & \\
\hline $60-64$ & $107(15.5)$ & 119 (17.9) & \\
\hline $65-69$ & $164(23.8)$ & $147(22.1)$ & \\
\hline $70-74$ & $155(22.5)$ & $124(18.7)$ & \\
\hline$\geq 75$ & $116(16.8)$ & $97(14.6)$ & \\
\hline \multicolumn{4}{|l|}{ Education (years) $^{b}$} \\
\hline$<7$ & $292(42.4)$ & $273(41.1)$ & \multirow{3}{*}{$p=0.80$} \\
\hline $7-11$ & $224(32.5)$ & $215(32.3)$ & \\
\hline$\geq 12$ & $173(25.1)$ & $177(26.6)$ & \\
\hline \multicolumn{4}{|l|}{ Tobacco Smoking $b$} \\
\hline Never-smokers & $96(14.1)$ & $237(35.6)$ & \multirow{6}{*}{$p<0.01$} \\
\hline Ex-smokers & $310(45.5)$ & $284(42.7)$ & \\
\hline Current smokers (cigarettes/day) & & & \\
\hline$<15$ & $79(11.6)$ & $53(8.0)$ & \\
\hline $15-24$ & $127(18.7)$ & $68(10.2)$ & \\
\hline$\geq 25$ & $69(10.1)$ & $23(3.5)$ & \\
\hline \multicolumn{4}{|l|}{ Alcohol Drinking (drinks/week) ${ }^{b}$} \\
\hline$<7$ & $159(23.1)$ & $184(27.7)$ & \multirow{4}{*}{$p=0.05$} \\
\hline $7-<14$ & $130(18.9)$ & $113(17.0)$ & \\
\hline $14-<28$ & $213(30.9)$ & $222(33.4)$ & \\
\hline$\geq 28$ & $187(27.1)$ & $145(21.8)$ & \\
\hline \multicolumn{4}{|l|}{ History of Diabetes } \\
\hline No & $578(83.8)$ & $608(91.4)$ & \multirow{2}{*}{$p<0.01$} \\
\hline Yes & $112(16.2)$ & $57(8.6)$ & \\
\hline \multicolumn{4}{|l|}{ History of Cystitis } \\
\hline No & $634(91.9)$ & $630(94.7)$ & \multirow{2}{*}{$p=0.04$} \\
\hline Yes & $56(8.1)$ & $35(5.3)$ & \\
\hline \multicolumn{4}{|l|}{ Family History Of Bladder Cancer ${ }^{c}$} \\
\hline No & $667(96.7)$ & $654(98.4)$ & \multirow{2}{*}{$p=0.05$} \\
\hline Yes & $23(3.3)$ & $11(1.6)$ & \\
\hline
\end{tabular}

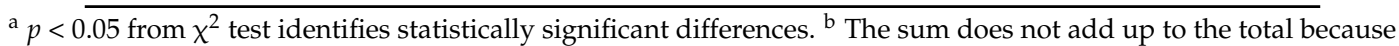
of some missing values. ${ }^{\mathrm{C}}$ Family history of bladder cancer in first-degree relatives.

The ORs were 0.72 (95\% CI, 0.54-0.98) for MDS = 4-5 and 0.66 (95\% CI, 0.47-0.93) for MDS = 6-9 compared to the lowest category (MDS $=0-3 ; p$-trend $=0.02$ ). The OR for 1-point increment of MDS was 0.89 (95\% CI, 0.83-0.96; Table 2). Accordingly, $12.6 \%$ (95\% CI: $-0.03 \%-28.4 \%$ ) of bladder cancer cases would have been avoided if all subjects were highly adherent to the Mediterranean diet (i.e., MDS = 6-9). The expected reduction would be of $11.1 \%$ shifting subjects to the lower adjacent MDS category. 
Table 2. Odds ratios (OR) and 95\% confidence intervals (CI) of bladder cancer according to Mediterranean diet score (MDS) among 690 bladder cancer cases and 665 controls. Italy, 2003-2014.

\begin{tabular}{cccc}
\hline & Cases (\%) & Controls (\%) & OR $\left.^{\mathbf{a}} \mathbf{( 9 5 \%} \mathbf{C I}\right)$ \\
\hline MDS $^{\mathrm{b}}$ & & & \\
$0-3$ & $182(26.4)$ & $127(19.1)$ & $1^{\mathrm{c}}$ \\
$4-5$ & $308(44.6)$ & $318(47.9)$ & $0.72(0.54-0.98)$ \\
$6-9$ & $200(29.0)$ & $219(33.0)$ & $0.66(0.47-0.93)$ \\
& & & $p$ trend $=0.02$ \\
1-point increment & & & $0.89(0.83-0.96)$ \\
\hline
\end{tabular}

a Estim748ates from unconditional logistic regression models adjusted for age, sex, study center, year of interview, education, tobacco smoking, body mass index, non-alcohol energy intake, history of diabetes, history of cystitis, and family history of bladder cancer. ${ }^{b}$ The sum does not add up to the total because of one missing value on the score. ${ }^{\mathrm{c}}$ Reference category.

Bladder cancer risk did not show significant heterogeneity across strata of sex, age, and education (Table 3). The inverse association with MDS was slightly stronger among never-smokers ( $p$-heterogeneity $=0.10)$ and among patients with pT1-pT4 tumors ( $p$-heterogeneity $=0.09)$. No significant heterogeneity emerged for tumor grade $(p$-heterogeneity $=0.30)$. Moreover, we estimated similar ORs in sensitivity analyses that excluded subjects with history of diabetes (OR for 1 point increment in the MDS = 0.92, $95 \%$ CI $0.85-1.00)$ or cystitis (OR $=0.90,95 \%$ CI $0.83-0.98)$.

Table 3. OR and 95\% CI of bladder cancer for 1 point increment in the MDS in strata of selected factors and according to tumor invasiveness and tumor grade. Italy, 2003-2014.

\begin{tabular}{|c|c|}
\hline & $\begin{array}{c}\text { OR }^{\text {a }}(95 \% \mathrm{CI}) \\
\text { MDS, 1-Point Increment }\end{array}$ \\
\hline $\begin{array}{l}\text { Age } \\
<70 \\
\geq 70\end{array}$ & $\begin{array}{c}0.90(0.82-0.99) \\
0.88(0.77-1.01) \\
p \text { heterogeneity }=0.89\end{array}$ \\
\hline $\begin{array}{c}\text { Sex } \\
\text { Men } \\
\text { Women }\end{array}$ & $\begin{array}{c}0.89(0.81-0.96) \\
0.81(0.64-1.01) \\
p \text { heterogeneity }=0.99\end{array}$ \\
\hline $\begin{array}{l}\text { Education (years) } \\
\qquad 77 \\
\quad \geq 7\end{array}$ & $\begin{array}{c}0.89(0.79-1.01) \\
0.88(0.79-0.97) \\
p \text { heterogeneity }=0.90\end{array}$ \\
\hline $\begin{array}{c}\text { Smoking Habits } \\
\text { Never } \\
\text { Ever, }<20 \text { cigarettes / day } \\
\text { Ever, } \geq 20 \text { cigarettes / day }\end{array}$ & $\begin{array}{c}0.71(0.58-0.87) \\
0.86(0.77-0.96) \\
0.98(0.86-1.11) \\
p \text { heterogeneity }=0.10\end{array}$ \\
\hline $\begin{array}{l}\text { Tumor Invasiveness } \\
\text { pTa/Tis } \\
\text { pT1-pT4 }\end{array}$ & $\begin{array}{c}0.95(0.86-1.05) \\
0.84(0.77-0.93) \\
p \text { heterogeneity }=0.09\end{array}$ \\
\hline $\begin{array}{c}\text { Tumor Grade } \\
\text { Well or moderately differentiated } \\
\text { Poorly differentiated or undifferentiated }\end{array}$ & $\begin{array}{c}0.93(0.84-1.02) \\
0.86(0.78-0.95) \\
p \text { heterogeneity }=0.30\end{array}$ \\
\hline
\end{tabular}

a Estimates from unconditional logistic regression models adjusted for age, sex, study center, year of interview, education, tobacco smoking, body mass index, non-alcohol energy intake, history of diabetes, history of cystitis, and family history of bladder cancer, when appropriate. 
When considering high vs. low consumption of the individual components of the MDS, we observed significant inverse associations for the intake of legumes ( $\mathrm{OR}=0.52,95 \% \mathrm{CI}, 0.40-0.69)$, vegetables $(\mathrm{OR}=0.70,95 \% \mathrm{CI}, 0.53-0.92)$ and fish $(\mathrm{OR}=0.68,95 \% \mathrm{CI}, 0.53-0.87)$; this is shown in supplementary Table S1.

\section{Discussion}

The findings from this Italian study indicate a favorable role of adherence to the Mediterranean diet on bladder cancer. Specifically, high adherence to such dietary pattern (i.e., MDS $\geq 6$ ) was associated with an almost 35\% reduced risk compared to low adherence (i.e., MDS of 0-3), with approximately $13 \%$ of bladder cancer cases attributable to a scanty adherence. Consistent results were observed in strata of relevant covariates; the inverse association with MDS appeared slightly, though not significantly, stronger for never-smokers and patients with pT1-pT4.

Only two other studies, both of which mainly based on non-Mediterranean populations, have previously investigated this dietary pattern on bladder cancer risk [24,25].

Findings from the European Prospective Investigation into Cancer and Nutrition (EPIC) cohort [24], which included 1425 incident bladder cancer cases, showed an inverse borderline association for high versus low adherence to the Mediterranean diet with a hazard ratio (HR) of 0.84 (95\% CI: 0.69-1.03) based on a modified version of the original Trichopoulou's score [32] (i.e., the 18-point rMED, which is based on the same nine components of the MDS, calculated as function of energy density, and divided into tertiles). Similar reduced risks were estimated for aggressive and nonaggressive tumors (i.e., non invasive vs invasive, HR: $0.88,95 \%$ CI: $0.61-1.28$ and HR: $0.78,95 \%$ CI: 0.54-1.14, respectively), while a more pronounced and significant inverse association was observed among current smokers (HR: 0.66, 95\% CI: 0.47-0.93), in particular among current heavy and long-term smokers (HR: 0.51, 95\% CI: 0.31-0.86). Although it is plausible that the antioxidants highly present in the Mediterranean diet may help to prevent or reduce the detrimental effect on DNA of free radicals and oxidant produced by tobacco smoking, these findings should be interpreted with caution and they are not entirely comparable with our results since only $29 \%$ of the EPIC study population came from Mediterranean areas. In addition, the Melbourne Collaborative Cohort Study (MCCS), which included 379 incident bladder cancer cases, reported no association between MDS and overall bladder cancer (HR for the 5th versus 1st quintile of the MDS: 0.89, 95\% CI, 0.62-1.26; HR for 1 SD increase in the score: $0.97,95 \% \mathrm{CI}, 0.87-1.07)$ or superficial cancer but an inverse association with invasive tumors (HR for the highest versus lowest quintile of the MDS: $0.67,95 \%$ CI, $0.46-1.14$; HR for $1 \mathrm{SD}$ increase in the score: $0.86,95 \% \mathrm{CI}, 0.74-1.00$ ) [25]. The association with invasive bladder cancer was apparently limited to former (HR for 1 SD increase: $0.80,95 \%$ CI, 0.67-0.95) and current smokers (HR: 0.82, 95\% CI: 0.63-1.05).

Although the present findings are not entirely comparable with that of the two abovementioned studies-mainly in consideration of the different populations (a typical Mediterranean population in our study vs. a European-wide population with less than a third of participants from southern Europe in the EPIC cohort and an Australian population with around 25\% of Italian or Greek descents in the MCCS study) and the different a priori scores used to assess the adherence to the dietary pattern-epidemiological data are suggestive of a favorable role of a high adherence to the Mediterranean diet against bladder cancer risk.

The role of diet on bladder carcinogenesis may be mediated by many metabolites of foods, which are excreted through the urinary tract. Previous studies-although not all—on bladder cancer have shown a protective role of high intakes of fruit and vegetables and selected nutrients related to these foods [11,37]. A favorable effect on bladder cancer of olive oil has also been suggested [38]. In addition, inverse associations were reported with the intake of legumes and whole-grains products [39], while a direct one was observed for a proinflammatory diet [40], supporting an anti-inflammatory role of the Mediterranean diet [41]. Indeed, the Mediterranean diet has been related to lower levels of inflammatory markers (such as C-reactive protein, interleukin-6, 
and adiponectin) as well as to a reduction in oxidative cells stress. A possible explanation lies in some Mediterranean diet components that may decrease postprandial oxidative levels, which are responsible for acute inflammation state [41-43]. With reference to other dietary factors considered in the development of the MDS, no clear associations with bladder cancer were reported for fish [44], alcohol [45], milk/dairy products [46], or meat [47].

The lack of information on physical activity, a recognized protective factor for bladder cancer risk [48], is a potential limitation of the present study. Moreover, people who are physically active tend to be more prone to healthy lifestyle habits in general, including dietary ones, and this may have influenced our estimates. However, we limited possible residual confounding adjusting for BMI, which is related to both diet and physical activity. Limitations of the present study also include possible selection and information biases, as in most case-control studies. To overcome such limitations, we did not include in the control group patients with diagnoses associated to long-term dietary modifications, alcohol drinking, and tobacco smoking. In addition, we selected cases and controls from the same catchment area and obtained a participation rate of over $95 \%$. Face-to-face interviews were conducted by trained interviewers within similar hospital settings for cases and controls to limit possible information bias. Strengths of our investigation include the evaluation of dietary habits of a southern European population where Mediterranean diet is still predominant, the use of a reproducible [29] and valid [28] FFQ, and data on several confounding factors available for adjustment purposes. However, a residual confounding effect of tobacco smoking and other lifestyle factors cannot be completely ruled out.

In conclusion, our investigation from Italy showed that an elevated adherence to the Mediterranean diet reduces bladder cancer risk.

Supplementary Materials: The following are available online at http:/ /www.mdpi.com/2072-6643/10/8/1061/ s1, Table S1: Odds ratios (OR) and 95\% confidence intervals (CI) of bladder cancer according to individual components of the Mediterranean diet score (MDS). Italy, 2003-2014.

Author Contributions: Conceptualization, F.T. and C.L.V.; Data curation, M.M., D.S., M.L., E.N.; Formal analyses F.T., F.B., and M.D.M.; Methodology, J.P., M.F., E.N.; Writing-Original Draft F.T., F.B., M.-E.S., M.D.M.; Writing-Review and Editing J.P., M.F., D.S., E.N. All authors read and approved the final content of the manuscript.

Funding: This work was supported by the Italian Foundation for Cancer Research (FIRC). We thank the Italian League against Cancer for the contribution to the project "Valutazione dell'effetto protettivo della Dieta mediterranea per i tumori della donna" Bando ricerca Sanitaria 2017-Cinque per mille anno 2015.

Conflicts of Interest: The authors declare no conflict of interest.

\section{References}

1. Ferlay, J.; Soerjomataram, I.; Dikshit, R.; Eser, S.; Mathers, C.; Rebelo, M.; Parkin, D.M.; Forman, D.; Bray, F. Cancer incidence and mortality worldwide: Sources, methods and major patterns in globocan 2012. Int. J. Cancer 2015, 136, 359-386. [CrossRef] [PubMed]

2. Van Osch, F.H.; Jochems, S.H.; van Schooten, F.J.; Bryan, R.T.; Zeegers, M.P. Quantified relations between exposure to tobacco smoking and bladder cancer risk: A meta-analysis of 89 observational studies. Int. J. Epidemiol. 2016, 45, 857-870. [CrossRef] [PubMed]

3. Al-Zalabani, A.H.; Stewart, K.F.; Wesselius, A.; Schols, A.M.; Zeegers, M.P. Modifiable risk factors for the prevention of bladder cancer: A systematic review of meta-analyses. Eur. J. Epidemiol. 2016, 31, 811-851. [CrossRef] [PubMed]

4. Burger, M.; Catto, J.W.; Dalbagni, G.; Grossman, H.B.; Herr, H.; Karakiewicz, P.; Kassouf, W.; Kiemeney, L.A.; La Vecchia, C.; Shariat, S.; et al. Epidemiology and risk factors of urothelial bladder cancer. Eur. Urol. 2013, 63, 234-241. [CrossRef] [PubMed]

5. Kogevinas, M.; Garcia-Closas, M.; Trichpoulos, D. Urinary bladder cancer. In Cancer Epidemiology, 2nd ed.; Adami, H.-O., Hunter, D., Trichpoulos, D., Eds.; Oxford Universiy Press: New York, NY, USA, 2008; pp. 573-596. 
6. Montella, M.; Di Maso, M.; Crispo, A.; Grimaldi, M.; Bosetti, C.; Turati, F.; Giudice, A.; Libra, M.; Serraino, D.; La Vecchia, C.; et al. Metabolic syndrome and the risk of urothelial carcinoma of the bladder: A case-control study. BMC Cancer 2015, 15, 720. [CrossRef] [PubMed]

7. Pelucchi, C.; Bosetti, C.; Negri, E.; Malvezzi, M.; La Vecchia, C. Mechanisms of disease: The epidemiology of bladder cancer. Nat. Clin. Pract. Urol. 2006, 3, 327-340. [CrossRef] [PubMed]

8. Silverman, D.T.; Devesa, S.S.; Moore, L.E.; Rothman, N. Bladder cancer. In Cancer Epidemiology and Prevention, 3rd ed.; Schottenfeld, D., Fraumeni, J.F., Jr., Eds.; Oxford University Press: New York, NY, USA, 2006; pp. 1101-1127.

9. Turati, F.; Bosetti, C.; Polesel, J.; Serraino, D.; Montella, M.; Libra, M.; Facchini, G.; Ferraroni, M.; Tavani, A.; La Vecchia, C.; et al. Family history of cancer and the risk of bladder cancer: A case-control study from Italy. Cancer Epidemiol. 2017, 48, 29-35. [CrossRef] [PubMed]

10. Turati, F.; Polesel, J.; Di Maso, M.; Montella, M.; Libra, M.; Grimaldi, M.; Tavani, A.; Serraino, D.; La Vecchia, C.; Bosetti, C. Diabetes mellitus and the risk of bladder cancer: An italian case-control study. Br. J. Cancer 2015, 113, 127-130. [CrossRef] [PubMed]

11. World Cancer Research Fund International/American Institute for Cancer Research. Continuous Update Project Report: Diet, Nutrition, Physical Activity and Bladder Cancer. 2015. Available online: Wcrf.Org/ bladder-cancer-2015 (accessed on 28 May 2018).

12. Xu, C.; Zeng, X.T.; Liu, T.Z.; Zhang, C.; Yang, Z.H.; Li, S.; Chen, X.Y. Fruits and vegetables intake and risk of bladder cancer: A prisma-compliant systematic review and dose-response meta-analysis of prospective cohort studies. Medicine 2015, 94, e759. [CrossRef] [PubMed]

13. Ros, M.M.; Bueno-de-Mesquita, H.B.; Kampman, E.; Aben, K.K.; Buchner, F.L.; Jansen, E.H.; van Gils, C.H.; Egevad, L.; Overvad, K.; Tjonneland, A.; et al. Plasma carotenoids and vitamin c concentrations and risk of urothelial cell carcinoma in the european prospective investigation into cancer and nutrition. Am. J. Clin. Nutr. 2012, 96, 902-910. [CrossRef] [PubMed]

14. Zamora-Ros, R.; Sacerdote, C.; Ricceri, F.; Weiderpass, E.; Roswall, N.; Buckland, G.; St-Jules, D.E.; Overvad, K.; Kyro, C.; Fagherazzi, G.; et al. Flavonoid and lignan intake in relation to bladder cancer risk in the European prospective investigation into cancer and nutrition (epic) study. Br. J. Cancer 2014, 111, 1870-1880. [CrossRef] [PubMed]

15. World Cancer Research Fund, American Institute for Cancer Research. Diet, Nutrition, Physical Activity and Cancer: A Global Prospective. Available online: http:/ / discovery.ucl.ac.uk/4841/1/4841.pdf (accessed on 28 May 2018).

16. Alicandro, G.; Tavani, A.; La Vecchia, C. Coffee and cancer risk: A summary overview. Eur. J. Cancer Prev. 2017, 26, 424-432. [CrossRef] [PubMed]

17. La Vecchia, C.; Bosetti, C. Diet and cancer risk in mediterranean countries: Open issues. Public Health Nutr. 2006, 9, 1077-1082. [CrossRef] [PubMed]

18. Willett, W.C.; Sacks, F.; Trichopoulou, A.; Drescher, G.; Ferro-Luzzi, A.; Helsing, E.; Trichopoulos, D. Mediterranean diet pyramid: A cultural model for healthy eating. Am. J. Clin. Nutr. 1995, 61, 1402S-1406S. [CrossRef] [PubMed]

19. Dernini, S.; Berry, E.M.; Serra-Majem, L.; La Vecchia, C.; Capone, R.; Medina, F.X.; Aranceta-Bartrina, J.; Belahsen, R.; Burlingame, B.; Calabrese, G.; et al. Med diet 4.0: The mediterranean diet with four sustainable benefits. Public Health Nutr. 2017, 20, 1322-1330. [CrossRef] [PubMed]

20. Giacosa, A.; Barale, R.; Bavaresco, L.; Gatenby, P.; Gerbi, V.; Janssens, J.; Johnston, B.; Kas, K.; La Vecchia, C.; Mainguet, P.; et al. Cancer prevention in europe: The mediterranean diet as a protective choice. Eur. J. Cancer Prev. 2013, 22, 90-95. [CrossRef] [PubMed]

21. La Vecchia, C. Association between mediterranean dietary patterns and cancer risk. Nutr. Rev. 2009, 67, S126-S129. [CrossRef] [PubMed]

22. Pelucchi, C.; Bosetti, C.; Rossi, M.; Negri, E.; La Vecchia, C. Selected aspects of mediterranean diet and cancer risk. Nutr. Cancer 2009, 61, 756-766. [CrossRef] [PubMed]

23. Schwingshackl, L.; Schwedhelm, C.; Galbete, C.; Hoffmann, G. Adherence to mediterranean diet and risk of cancer: An updated systematic review and meta-analysis. Nutrients 2017, 9, 1063. [CrossRef] [PubMed]

24. Buckland, G.; Ros, M.M.; Roswall, N.; Bueno-de-Mesquita, H.B.; Travier, N.; Tjonneland, A.; Kiemeney, L.A.; Sacerdote, C.; Tumino, R.; Ljungberg, B.; et al. Adherence to the mediterranean diet and risk of bladder cancer in the epic cohort study. Int. J. Cancer 2014, 134, 2504-2511. [CrossRef] [PubMed] 
25. Dugue, P.A.; Hodge, A.M.; Brinkman, M.T.; Bassett, J.K.; Shivappa, N.; Hebert, J.R.; Hopper, J.L.; English, D.R.; Milne, R.L.; Giles, G.G. Association between selected dietary scores and the risk of urothelial cell carcinoma: A prospective cohort study. Int. J. Cancer 2016, 139, 1251-1260. [CrossRef] [PubMed]

26. Polesel, J.; Bosetti, C.; di Maso, M.; Montella, M.; Libra, M.; Garbeglio, A.; Zucchetto, A.; Turati, F.; Talamini, R.; La Vecchia, C.; et al. Duration and intensity of tobacco smoking and the risk of papillary and non-papillary transitional cell carcinoma of the bladder. Cancer Causes Control 2014, 25, 1151-1158. [CrossRef] [PubMed]

27. Moch, H.; Humphrey, P.A.; Ulbright, T.M.; Reuter, V. Who Classification of Tumours of the Urinary System and Male Genital Organs. International Agency for Research on Cancer (IARC): Lyon, France, 2016. Available online: http: / / apps.who.int/bookorders /WHP / detart1.jsp?sesslan=1\&codlan=1\&codcol=70\&codcch=4008 (accessed on 28 May 2018).

28. Decarli, A.; Franceschi, S.; Ferraroni, M.; Gnagnarella, P.; Parpinel, M.T.; La Vecchia, C.; Negri, E.; Salvini, S.; Falcini, F.; Giacosa, A. Validation of a food-frequency questionnaire to assess dietary intakes in cancer studies in italy. Results for specific nutrients. Ann. Epidemiol. 1996, 6, 110-118. [CrossRef]

29. Franceschi, S.; Negri, E.; Salvini, S.; Decarli, A.; Ferraroni, M.; Filiberti, R.; Giacosa, A.; Talamini, R.; Nanni, O.; Panarello, G.; et al. Reproducibility of an italian food frequency questionnaire for cancer studies: Results for specific food items. Eur. J. Cancer 1993, 29, 2298-2305. [CrossRef]

30. Gnagnarella, P.; Parpinel, M.; Salvini, S.; Franceschi, S.; Palli, D.; Boyle, P. The update of the italian food composition database. J. Food Compost. Anal. 2004, 17, 509-522. [CrossRef]

31. Salvini, S.; Parpinel, M.; Gnagnarella, P.; Maisonneuve, P.; Turrini, A. Banca di Composizione Degli Alimenti per Studi Epidemiologici in Italia; Istituto Europeo di Oncologia: Milano, Italia, 1998; Available online: http:/ / agris.fao.org/agris-search/search.do?recordID=XF2015019268 (accessed on 28 May 2018).

32. Trichopoulou, A.; Costacou, T.; Bamia, C.; Trichopoulos, D. Adherence to a mediterranean diet and survival in a Greek population. N. Engl. J. Med. 2003, 348, 2599-2608. [CrossRef] [PubMed]

33. Bruzzi, P.; Green, S.B.; Byar, D.P.; Brinton, L.A.; Schairer, C. Estimating the population attributable risk for multiple risk factors using case-control data. Am. J. Epidemiol. 1985, 122, 904-914. [CrossRef] [PubMed]

34. Benichou, J.; Gail, M.H. Variance calculations and confidence intervals for estimates of the attributable risk based on logistic models. Biometrics 1990, 46, 991-1003. [CrossRef] [PubMed]

35. Mezzetti, M.; Ferraroni, M.; Decarli, A.; La Vecchia, C.; Benichou, J. Software for attributable risk and confidence interval estimation in case-control studies. Comput. Biomed. Res. 1996, 29, 63-75. [CrossRef] [PubMed]

36. Bosetti, C.; Tzonou, A.; Lagiou, P.; Negri, E.; Trichopoulos, D.; Hsieh, C.C. Fraction of prostate cancer incidence attributed to diet in athens, greece. Eur. J. Cancer Prev. 2000, 9, 119-123. [CrossRef] [PubMed]

37. Liu, H.; Wang, X.C.; Hu, G.H.; Guo, Z.F.; Lai, P.; Xu, L.; Huang, T.B.; Xu, Y.F. Fruit and vegetable consumption and risk of bladder cancer: An updated meta-analysis of observational studies. Eur. J. Cancer Prev. 2015, 24, 508-516. [CrossRef] [PubMed]

38. Brinkman, M.T.; Buntinx, F.; Kellen, E.; Van Dongen, M.C.; Dagnelie, P.C.; Muls, E.; Zeegers, M.P. Consumption of animal products, olive oil and dietary fat and results from the belgian case-control study on bladder cancer risk. Eur. J. Cancer 2011, 47, 436-442. [CrossRef] [PubMed]

39. Augustin, L.S.A.; Taborelli, M.; Montella, M.; Libra, M.; La Vecchia, C.; Tavani, A.; Crispo, A.; Grimaldi, M.; Facchini, G.; Jenkins, D.J.A.; et al. Associations of dietary carbohydrates, glycaemic index and glycaemic load with risk of bladder cancer: A case-control study. Br. J. Nutr. 2017, 118, 722-729. [CrossRef] [PubMed]

40. Shivappa, N.; Hebert, J.R.; Rosato, V.; Rossi, M.; Libra, M.; Montella, M.; Serraino, D.; La Vecchia, C. Dietary inflammatory index and risk of bladder cancer in a large italian case-control study. Urology 2017, 100, 84-89. [CrossRef] [PubMed]

41. Estruch, R. Anti-inflammatory effects of the mediterranean diet: The experience of the predimed study. Proc. Nutr. Soc. 2010, 69, 333-340. [CrossRef] [PubMed]

42. Perez-Martinez, P.; Garcia-Quintana, J.M.; Yubero-Serrano, E.M.; Tasset-Cuevas, I.; Tunez, I.; Garcia-Rios, A.; Delgado-Lista, J.; Marin, C.; Perez-Jimenez, F.; Roche, H.M.; et al. Postprandial oxidative stress is modified by dietary fat: Evidence from a human intervention study. Clin. Sci. 2010, 119, 251-261. [CrossRef] [PubMed]

43. Schwingshackl, L.; Hoffmann, G. Mediterranean dietary pattern, inflammation and endothelial function: A systematic review and meta-analysis of intervention trials. Nutr. Metab. Cardiovasc. Dis. 2014, 24, 929-939. [CrossRef] [PubMed] 
44. Li, Z.; Yu, J.; Miao, Q.; Sun, S.; Sun, L.; Yang, H.; Hou, L. The association of fish consumption with bladder cancer risk: A meta-analysis. World J. Surg. Oncol. 2011, 9, 107. [CrossRef] [PubMed]

45. Pelucchi, C.; Galeone, C.; Tramacere, I.; Bagnardi, V.; Negri, E.; Islami, F.; Scotti, L.; Bellocco, R.; Corrao, G.; Boffetta, P.; et al. Alcohol drinking and bladder cancer risk: A meta-analysis. Ann. Oncol. 2012, 23, 1586-1593. [CrossRef] [PubMed]

46. Li, F.; An, S.L.; Zhou, Y.; Liang, Z.K.; Jiao, Z.J.; Jing, Y.M.; Wan, P.; Shi, X.J.; Tan, W.L. Milk and dairy consumption and risk of bladder cancer: A meta-analysis. Urology 2011, 78, 1298-1305. [CrossRef] [PubMed]

47. Crippa, A.; Larsson, S.C.; Discacciati, A.; Wolk, A.; Orsini, N. Red and processed meat consumption and risk of bladder cancer: A dose-response meta-analysis of epidemiological studies. Eur. J. Nutr. 2018, 57, 689-701. [CrossRef] [PubMed]

48. Keimling, M.; Behrens, G.; Schmid, D.; Jochem, C.; Leitzmann, M.F. The association between physical activity and bladder cancer: Systematic review and meta-analysis. Br. J. Cancer 2014, 110, 1862-1870. [CrossRef] [PubMed]

(C) 2018 by the authors. Licensee MDPI, Basel, Switzerland. This article is an open access article distributed under the terms and conditions of the Creative Commons Attribution (CC BY) license (http:/ / creativecommons.org/licenses/by/4.0/). 